\title{
IMPLEMENTASI LEAN DENGAN MENGGUNAKAN VALUE STREAM MAPPING UNTUK MEMPERCEPAT LEAD TIME PROSES OUTBOUND DI PT.X
}

\author{
${ }^{1 .}$ Tri Widodo, ${ }^{2}$ Ismail Ferdiansyah \\ Staff Pengajar Program Studi Teknik Industri, Fakultas Teknik \\ Universitas Muhammadiyah Tangerang \\ Jl. Perintis Kemerdekaan I/33, Cikokol, Kota Tangerang
}

\begin{abstract}
Abstrak
PT X merupakan perusahaan yang bergerak di bidang penyedia pelayanan logistik, salah satu divisinya adalah contract logistic, yang mengurusi kontrak warehousing dengan para pelanggannya. Operasional yang ada di warehouse meliputi inbound, storaging, dan outbound.agar dapat bersaing dan memenuhi keinginan pelanggannya, PT.X harus mampu melaksanakan operasionalnya secara efektif dan efisien. Salah satu upaya untuk terlaksananya proses yang efektif dan efisien adalah dengan mengimplementasikan lean. Penelitian ini membahas mengenai implementasi lean pada proses outbound di PT.X. implementasi lean dengan menggunakan value stream mapping.

Penggunaan value stream mapping pada proses outbound untuk mengidentifikasi pemborosan mandapatkan hasil antara lain : total lead time yang dibutuhkan untuk proses outbound saat ini sebesar 13.286 detik dengan value added ratioyang didapat sebesar 6,68\%. Berangkat dari kondisi saat ini, maka dirancang future state mapping untuk mendapatkan kondisi ideal. Berdasarkan perancangan future state mapping yang dibuat, maka diketahui lead time yang didapat adalah sebesar 1.192 detik dengan value added ratio sebesar 23,08\%.Untuk dapat merealisasikan future state mapping yang dirancang atau kondisi ideal, perusahaan memerlukan upaya-upaya penghilangan pemborosan pada setiap aktivitas yang ada di proses outbound.
\end{abstract}

Kata Kunci :Current state Mapping, Future State Mapping, Value added ratio

\begin{abstract}
PT.X is a logistic service provider company. One of their division is a contract logistic. Contract logistic is division that maintain the warehouse of customer. Operation in warehouse customer that handle by contract logistic consist of inbound, storage, and outbound. to be competitiveness and meet the customer requirement, PT.X should be effective and efficient in Operation. It canbe happen through by lean implementation. This research explain about lean implementation in outbound process at PT.X.

The result of value stream mapping in outbound process to identify and eliminate waste in outbound process are total lead time outbound process are 13.286 second with value added ratio by 6,68 \%. Regarding this fact, future state mapping has created. The result of future state mapping consist of the total lead time in outbound process are 1.192 second with value added ratio by 23,08\%. To achieve the benefit of future state mapping, the management needs focus to eliminate all waste for each activity in outbound process.

Key word:Current state Mapping, Future State Mapping, Value added ratio
\end{abstract}

Terima 5 Juli 2017, Revisi 14 Juli 2017, Disetujui 20 Juli 2017 


\section{PENDAHULUAN}

Pada era modern sekarang ini situasi dunia industri manufaktur maupun jasa mengalami persaingan yang sangat ketat . alex, lokesh dan ravikumar(2010) mengemukakan bahwa karakter dari ketatnya persaingan industri dipicu oleh cepatnya inovasi teknologi yang terjadi, dan perubahan kebutuhan pelanggan. Sehingga seluruh pelaku industri berusaha untuk mencapai kinerja kelas dunia melalui upaya pengurangan pemborosan dan perbaikan terus menerus pada operasionalnya.

Upaya pengurangan pemborosan merupakan implementasi dari system lean manufacture (satao,dkk, 2012). Erfan (2010) juga mengemukakan bahwa pemborosan sendiri mengandung makna segala kegiatan yang tidak memberikan nilai tambah kepada pelanggan atau non value added.

PT X merupakan perusahaan yang bergerak di bidang penyedia pelayanan logistik, salah satu divisinya adalah contract logistic, yang mengurusi kontrak warehousing dengan para pelanggannya. Operasional yang ada di warehouse meliputi inbound, storaging, dan outbound.

Jika kita analisa lebih detail tentang urutan aktivitas pada proses outbound maka akan didapat beberapa aktivitas, antara lain :Picking, Packing, dispatching dan Unloading. Rata-rata waktu untuk menyelesaikan proses outbound di warehouse dibutuhkan leadtime sebanyak 2 hari. Hal ini tentunya merupakan pemborosan, karena waktu tunggu yang sangat tinggi. Selain itu juga akan ditemukan WIP di setiap masing-masing aktivitas pada proses outbound, karena stasiun kerja aktivitas yang satu dan yang lainnya yang cukup berjauhan, hal ini merupakan pemborosan dengan kategori persediaan. Dan secara jelas juga dapat dilihat bahwa terjadi pemborosan reproses, karena seluruh produk yang akan dikirim akan melalui proses check yang berulang-ulang.

Pemborosan yang terjadi dapat di atasi dengan penerapan lean manufacturing menggunakanValue Stream Mapping (VSM). Menurut erfan (2010) yang menyatakan bahwa value stream mapping merupakan salah satu alat dalam lean yang paling ideal digunakan untuk mengidentifikasi dan mengurangi pemborosan yang terjadi. beliau mengemukakan bahwa dengan menerapkan VSM dapat mereduksi leadtime hingga 20,7\%, meningkatkan 50\% kapasitas, dan mereduksi $36 \%$ idle time atau waktu tunggu.

Berangkat dari fenomena ini, penelitian dilakukan dengan menganalisa proses outbound menggunakan value stream mapping dalam upaya mengidentifikasi dan mengurangi pemborosan yang terjadi pada PT.X

\section{METODOLOGI}

\section{Pengumpulan data}

tahap ini mulailah dilakukan langkah-langkah pengumpulan data yangdibutuhkan untuk mencapai tujuan penelitian. Jenis data yang di ambil pun terbagimenjadi dua, yaitu data primer dan data sekunder

a. Pengumpulan Data Primer

Data primer yang diambil antara lain adalah gemba yaitu dengan melihat kondisi aktual alur proses dan mengidentifikasi pemborosan yang terjadi. Lalu dengan melakukan pengukuran cycle time untuk seluruh aktitivitas.

b. Pengumpulan Data sekunder

Data sekunder yang diambil adalah data order line yang harus diselesaikan, data jumlah karyawan

\section{Pembuatan Peta Kondisi Saat ini.}

Pada tahap ini dilakukan pembuatan peta dari data-data yang telah didapat.Pembuatan peta aliran material dan aluran informasi yang terjadi.

Perhitungan Value added ratioTahap ini dilakukan perhitungan value added ratio untuk keseluruhan proses outbounddengan membandingkan jumlah waktu yang memiliki nilai tambah terhadap keseluruhan waktu proses outbound.

JIM, Vol. 2, No. 2, Juli 2017, pp.82-88 


\section{Perancangan Peta kondisi yang akan datang}

Pada tahap ini dilakukan pembuatan desain peta aliran material maupun informasiuntuk masa depan berdasarkan prinsip-prinsip lean. kondisi mendatang yang diharapkan adalah kondisi dimana proses bisa berjalan lebih ramping. Artinya aliran material dan aliran informasi bisa berjalanlebih ramping dan secara langsung dapat mengurangi pemborosan ataupun mencegahpemborosan dapat terjadi.

\section{Rencana Perbaikan}

telah desain ditetapkanmaka dibuat juga rencana tindakan untuk mencapai desain masa depan tersebut.

\section{HASIL DAN PEMBAHASAN}

Hasil yang didapat pada penelitian ini antara lain :

\section{Peta Kondisi Saat ini atau Current State Mapping}

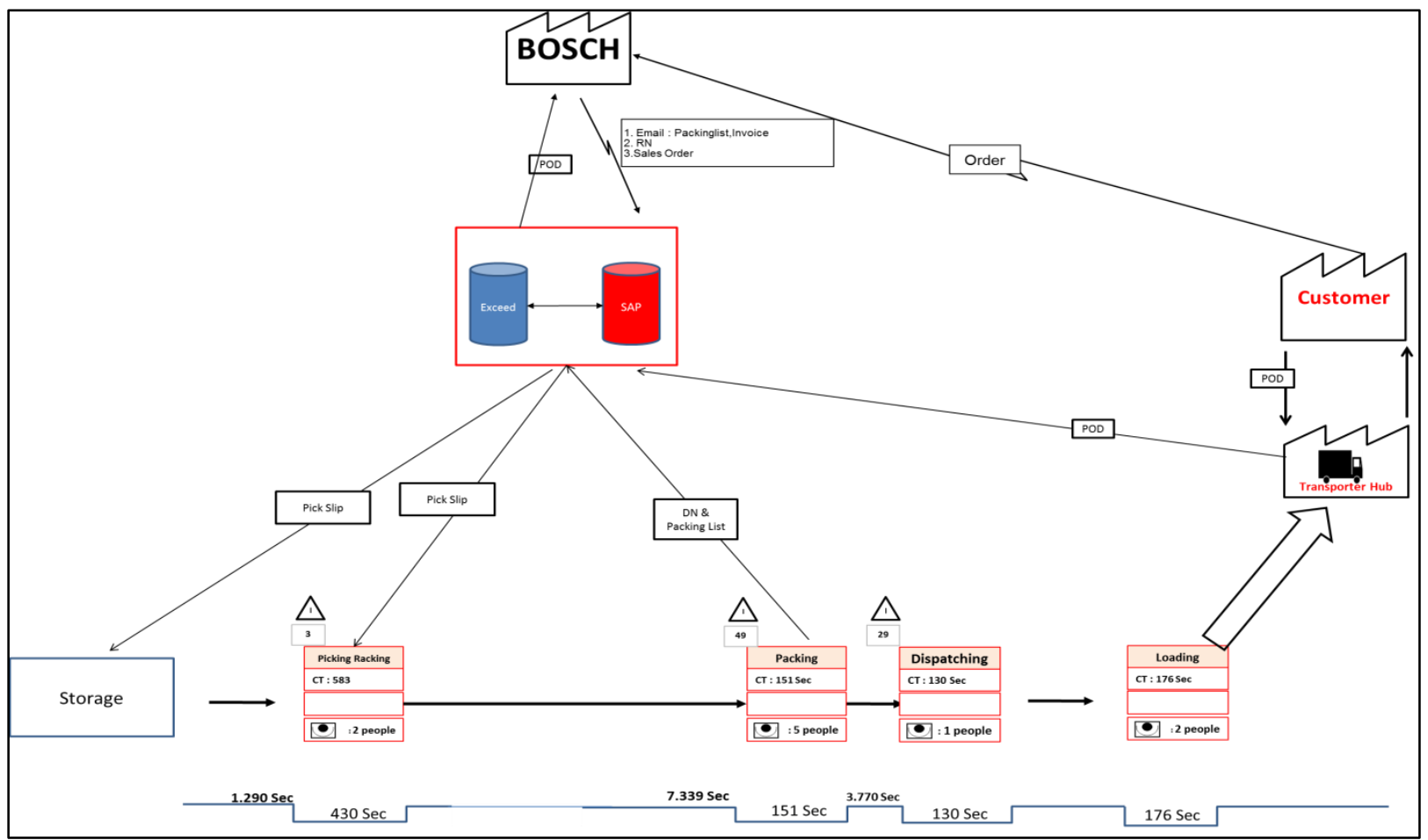

Gambar 1. Peta Kondisi Saat ini

Dari gambar diatas dapat dilihat bahwa aliran material dan aliran informasi yang terjadi saat ini,

\section{Perhitungan Value Added Ratio}

dengan perhitungan value added ratio sebagai berikut :

Tabel.1 hasil perhitungan Value Added Ratio current state

\begin{tabular}{|c|c|}
\hline KPI & Result \\
\hline Total Lead Time (Second) & 13286 \\
\hline Value Added Time (Second) & 887 \\
\hline Value Added Ratio & $6.68 \%$ \\
\hline
\end{tabular}


Dari tabel perhitungan diatas,kita dapat melihat bahwa rasio waktu yang bernilai tambah terhadap kesuluruhan lead time sangat kecil, yaitu hanya 6,68\%. maka dari itu upaya pengurangan pemborosan atau implementasi lean sangatlah diperlukan dengan tujuan mengurangi lead time sehingga dapat mempercepat proses outbound.

\section{Perancangan Future State Mapping}

Perancangan peta kondisi yang akan dilakukan dengan mengeliminasi seluruh

pemborosan yang terjadi dimasing-masing aktivitas, serta penggabungan beberapa proses yang memungkinkan untuk digabung dengan memperhatikan takt time sebagai acuan.

Berikut adalah gambar Peta Kondisi yang akan datang atau future state mapping :

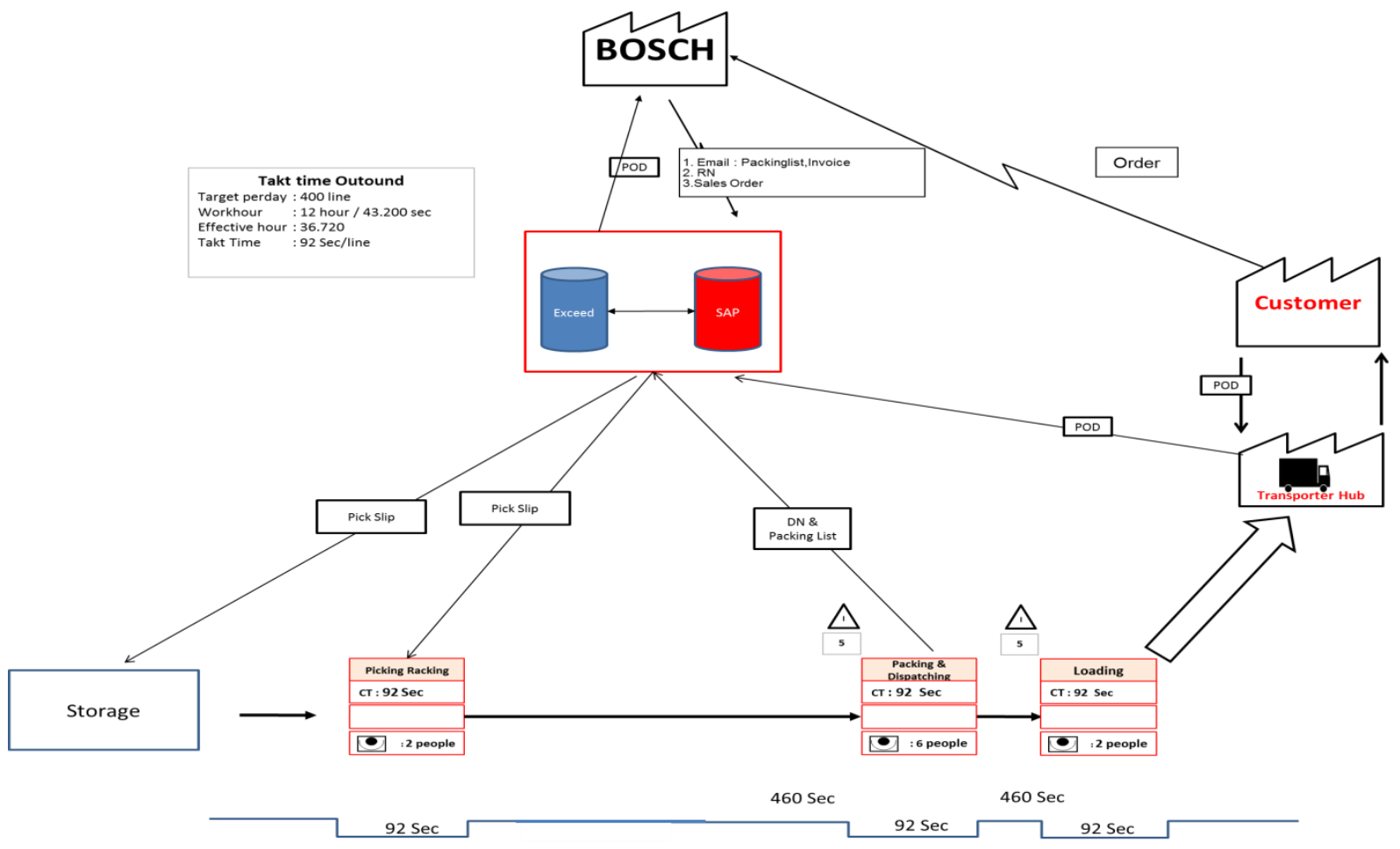

Gambar 2. Peta Kondisi yang akan dating atau future state Mapping

Dari gambar future state mapping yang ada diatas, diketahui perhitungan value added ratio adalah sebagai berikut :

Tabel 2. Hasil perhitungan Value added ratio future state

\begin{tabular}{|c|c|}
\hline KPI & Result \\
\hline Total Lead Time (Second) & 1196 \\
\hline Value Added Time (Second) & 276 \\
\hline Value Added Ratio & $23.08 \%$ \\
\hline
\end{tabular}

JIM, Vol. 2, No. 2, Juli 2017, pp.82-88 
Dalam menetapkan future state, takt time menjadi hal yang diperhatian. Takt time untuk proses outbound adalah waktu kerja efektif selama satu hari yaitu 36.720 detik dibagi dengan target order line perhari sebanyak 400 order, maka didapat takt time sebesar 92 detik per order line.

Future state mapping sangat memungkinkan untuk diimplementasikan dikarenakan pemborosan yang terjadi pada masing-masing aktivitas dapat dikurangi dan disesuaikan dengan takt time yang didapat.

\section{Perbandingan Current state Mapping dan Future State Mapping}

Dari hasil perbandingan diatas dapat dilihat bahwa terjadi penurunan total lead time dari 13.286 detik menjadi 1196 detik, sertaterjadi peningkatan value added ratio dari 6,68\% menjadi $23,08 \%$.

Tabel 3. Perbandingan current dan future state mapping

\begin{tabular}{|c|c|c|}
\hline KPI & Current & Future \\
\hline Total Lead Time (Second) & 13286 & 1196 \\
\hline Value Added Time (Second) & 887 & 276 \\
\hline Value Added Ratio & $6.68 \%$ & $23.08 \%$ \\
\hline
\end{tabular}

\section{Rencana Perbaikan}

Untuk merealisasikan future state mapping dari kondisi saat ini yang tergambar di current state mapping, diperlukan beberapa rencana perbaikan. Rencana perbaikan ini juga menjadi tantangan tersendiri bagi perusahaan agar value stream mapping yang telah dibuat benar-benar memberikan manfaat bagi perusahaan dalam upaya pengurangan pemborosan yang terjadi. Rencana perbaikan tersebut antara lain :

1. Proses penggabungan antara proses packing dan proses dispatching. Karena pada hakikatnya proses dispatching adalah proses double check, dan sangat memungkinkan untuk dilakukan saat proses packing berlangsung.

2. Pengurangan pemborosan transportasi di aktivitas loading, yaitu dengan merelayout kendaraan yang akan digunakan untuk melakukan proses loading. Dan meminimalisir waktu menunggu untuk mencari peralatan administrasi loading dengan memfasilitasi peralatan tersebut agar mudah untuk digunakan.

3. Mengurangi pemborosan yang terjadi di proses packing khususnya pemborosan yang sifatnya over motion. Hal ini dapat dilakukan dengan memodifikasi tempat kerja atau area kerja operator. Serta memfasilitasi alat bantu dalam pengerjaan proses packing.

4. Mengurangi pemborosan yang terjadi diproses picking khususnya pemborosan yang sifatnya waiting. Karena operator harus mencari material yang harus di picking. Hal ini dapat dipecahkan dengan menerapkan system pick fast untuk material yang fast moving.

\section{KESIMPULAN DAN SARAN}

Kesimpulan yang dapat diambil dari penelitian ini antara lain :

1. Kondisi saat ini pada Proses outbound di warehouse PT. X memerlukan lead time sebesar 13.286 detik, dengan value added ratio sebesar $6,68 \%$. 
2. Dengan mengimplementasikan future state mapping yang dibuat maka lead time proses outbound di warehouse PT.X menjadi lebih cepat yaitu sebesar 1.196 detik dengan value added ratio sebesar $23,08 \%$.

3. Realisasi untuk mencapai future state yang telah dirancang, dibutuhkan usaha yang besar melalui upaya pengurangan pemborosan pada setiap masing-masing aktivitas pada proses outbound.

Adapun saran yang bisa diberikan untukperusahaan antara lain :

1. Rencana perbaikan unuk mencapai future state mapping dapat dijadikan sebagai fokus atau target bagi seluruh jajaran yang ada di perusahaan.

2. Memperkenalkan lebih jauh mengenai pemborosan-pemborosan yang terjadi serta upaya untuk menguranginya.

\section{DAFTAR PUSTAKA}

Alex, S., Lokesh, C. A., Ravikumar, N., (2010).Space utilization improvement in CNC machining unit through lean layout.Sastech Journal, 9(2).

Anvar, M. M., \& Irannejad, P. P., (2010).Value stream mapping in chemical processes: A case study in Akzonobel Surface Chemistry, Stenungsud,Sweden.Proceedings of the Lean Advancement Initiative, Daytona Beach,Florida.

Bhat, R., \& Shivakumar, S., (2011). Improving the productivity using valuestream mapping and kanban approach.International Journal of Scientific \&Engineering Research, 2(8), 22295518.

Chen, L., \& Meng, B., (2010). The application of value stream mapping basedlean production system. International Journal of Business and Management,5(6).

Erfan, M. O., (2010). Application of lean manufacturing to improve theperformance of health care sector in Libya.International Journal ofEngineering \& Technology, 10(06), 101706-6868.

Goriwondo, M. W., \& Maunga, N., (2012). Lean six sigma application forsustainable production : A case study for margarine production inZimbabwe. International Journal Innovative Technology and ExploringEngineering, 1 (5), 2278-3075.

Goriwondo, M. W., Mhlanga, S., Marecha, A., (2011). Use of the value streammapping tool for waste reduction in manufacturing.Case study for breadmanufacturing in Zimbabwe.The Proceedings of the InternationalConfrence on Industrial engineering and Operation Management, KualaLumpur, Malaysia.

Haque, A., Chakrabortty, K. R., Hosain, M., Mondal, P., \& Islam, A. S., (2012).Implementation of Lean tools in RMG sector through value stream mapping(VSM) for increasing value added activities. World Journal of SocialSciences, 2(5), 225-234.

Kadam, J. S., Shende, N., \& Kamble, D. P., (2012). Value stream mapping toolfor waste identification in tyre-rim assembly of tractor manufacturing.International Confrence on Emerging Frontiers in Technology for RuralArea, Nagpur, India : Yeshwantro chavan College.

Krishnan, P. V., Ramnath, B., \& Pillai, K., (2011). Work in process optimisationthrough lean manufacturing. International Journal of Economic Research,2(2), 19-25.

Liker, K. J., \& Meier, D. (2006). The toyota way fieldbook a practical guide forimplementing toyota's 4Ps. New york : Mc Graw-Hill

Ramesh, V., Prasad, K. V., \& Srinivas, T. R, (2008). Implementaion and Leanmodel for carrying out value stream mapping in a manufacturing industry.Journal of Industrial and Systems engineering, 2 (3), 180-196.

JIM, Vol. 2, No. 2, Juli 2017, pp.85-91 
Rathaur, G., Rohit, K., Dandekar, D. M., \& Dalpati, A., (2012). Mapping thecurrent state value stream : A case study of a manufacturing unit. NationalConfrence on Emerging Challenges for Sustainable Business, (ISBN-978-81583-46-3).

Revelle, B. J. (2002). Manufacturing handbook of best practices an innovation,productivity, and quality focus. Florida: CRC Press LLC

Rother, M., \& Shook, J. (2004).Learning to see : Value Stream mapping to createvalue and eliminate muda version 1.4. Cambridge : Lean EnterpriseInstitute.

Satao, M. S., Thampi, T. G., Dalvi, D. S., Srinivas, B., \& Patil, T. B., (2012).Enhancing waste reduction through lean manufacturing tools andtechniques, a methodical step in the territory of green manufacturing.International Journal of Research in Management and Technologiy, 2(2),2249- 9563 .

Singh, G., Belokar, M. R., (2012). Lean manufacturing implementation in theassembly shop of tractor manufacturing company. International JournalInnovative Technology and Exploring Engineering,1(2), 2278-3075.

Sun, S. (2011). The strategic role of lean production in SOE's Development.International Journal of Business and Management, 6(2), 1833-3850.The Seven Waste be lean by identifying non value added activities. (2009, Oktober). Isixsigma Magazine. 